\title{
Research Methods in Weed Science
}

It was 58 yr ago (1956) when the Weed Science Society of America was formally organized in the United States. This served to unify the regional organizations of weed scientists, which were formed independently earlier in the 20th century, in North America and likewise in Canada, to pursue a common mission and vision. As the discipline expanded and evolved with discoveries of herbicidal chemistries, the Southern Weed Science Society (SWSS) published a manual on Research Methods in Weed Science in the 1960s, which quickly progressed to a second edition in 1971 with 198 pages. An expanded, third edition was printed in 1986 with 486 pages. Basic principles of experimentation and many research techniques were carried through time. Outdated ones have long been modified or entirely superseded by modern approaches using modern instrumentation or equipment. The science has become more complex, and we are now able to investigate the smallest molecule and tease out the most basic processes in living organisms. We have entered the era of genomic, nano, and geospatial technologies, among other areas, which still need to be anchored to whole-plant and landscape processes. The discipline is now populated with a new generation of scientists and the Internet has facilitated the globalization of Weed Science. No single reference, however, encompasses current approaches in weed science research. Thus, the idea of assembling a Special Issue on Weed Science Research Methods was born. A large team of weed scientists from many nations was assembled to help accomplish the task.

The goal of this project is to produce a consolidated reference, authored by experts in various fields of weed science, which will present updated protocols for designing and conducting weed science experiments as well as analyzing research data. Uncertainties and differing opinions abound regarding various approaches to the planning and implementation of weed science experiments. Having one reference containing recommended protocols for different experiments is invaluable to students and young weed scientists. We hope the updated protocols will also be helpful to senior weed scientists who are learning new areas in weed science, or new approaches to weed science experimentation.

We are indebted to Robert E. Wilkinson and Nyal Dwight Camper, editors of the previous editions of Research Methods in Weed Science, who carried the mission of advancing the science through proper research techniques. We are also indebted to all the scientists who contributed to the compilation of various sections of this 2015 version of the Research Methods in Weed Science. This project is made possible by the sponsorship of the Weed Science Society of America.

Special Issue Associate Editors:

Nilda Roma-Burgos, University of Arkansas, Fayetteville, AR, USA

Stephen O. Duke, USDA-ARS, Oxford, MS, USA

DOI: $10.1614 /$ wees-13-00-13.1

Introduction to the Special Issue 